\title{
GABAergic/glutamatergic imbalance relative to excessive neuroinflammation in autism spectrum disorders
}

Afaf El-Ansary ${ }^{1,2,3,5^{*}}$ and Laila Al-Ayadhi 2,3,4 $^{2}$

\begin{abstract}
Background: Autism spectrum disorder (ASD) is characterized by three core behavioral domains: social deficits, impaired communication, and repetitive behaviors. Glutamatergic/GABAergic imbalance has been found in various preclinical models of ASD. Additionally, autoimmunity immune dysfunction, and neuroinflammation are also considered as etiological mechanisms of this disorder. This study aimed to elucidate the relationship between glutamatergic/ GABAergic imbalance and neuroinflammation as two recently-discovered autism-related etiological mechanisms.

Methods: Twenty autistic patients aged 3 to 15 years and 19 age- and gender-matched healthy controls were included in this study. The plasma levels of glutamate, GABA and glutamate/GABA ratio as markers of excitotoxicity together with TNF-a, IL-6, IFN- $\gamma$ and IFI16 as markers of neuroinflammation were determined in both groups.

Results: Autistic patients exhibited glutamate excitotoxicity based on a much higher glutamate concentration in the autistic patients than in the control subjects. Unexpectedly higher GABA and lower glutamate/GABA levels were recorded in autistic patients compared to control subjects. TNF- $a$ and IL-6 were significantly lower, whereas IFN- $\gamma$ and IFI16 were remarkably higher in the autistic patients than in the control subjects.

Conclusion: Multiple regression analysis revealed associations between reduced GABA level, neuroinflammation and glutamate excitotoxicity. This study indicates that autism is a developmental synaptic disorder showing imbalance in GABAergic and glutamatergic synapses as a consequence of neuroinflammation.
\end{abstract}

Keywords: Autism, Glutamate excitotoxicity, Gamma aminobutyric acid (GABA), Glutamate/GABA, Tumor necrosis factor-a, Interleukin-6, Interferon-gamma, Interferon-gamma-inducible protein 16

\section{Introduction}

The brain's immune system is controlled by the microglia, a set of cells that when activated can secrete numerous cytokines, chemokines, eicosanoids, proteases, complement and excitotoxins [1]. It is well known that microglial immune cytokines can be activated by, heavy metals (for example, mercury), amyloid, bacteria, and glutamate. During neurodevelopment, the immune cytokines can act as neurotrophic substances, protecting and promoting neurite growth. With excess activation and when chronically activated, these cytokines can be very destructive.

\footnotetext{
* Correspondence: elansary@ksu.edu.sa

'Biochemistry Department, Science College, King Saud University, PO box 22452, 11495 Riyadh, Saudi Arabia

${ }^{2}$ Autism Research and Treatment Center, Riyadh, Saudi Arabia

Full list of author information is available at the end of the article
}

An autotoxic, non-specific immune destruction of neurons, neurites and synaptic connections has been described by McGeer et al. [2]. In this process, either systemic immune factors (cytokines) or local immune factors, such as beta-amyloidcan activate the brain's immune system via activation of astrocytes and microglia. In both instances brain levels of cytokines, reactive oxygen and nitrogen species, cellular immune components, excitotoxins and arachidonic acid are elevated leading to brain dysfunction.

The difference in severity between patients with autism appears to vary with the stage at which the immune/excitotoxic stress arises and its intensity. In humans, it is well known that a considerable amount of postnatal brain development occurs, with the highest synaptogenesis occurring during the last trimester and the first two 
postnatal years. An excess of extraneuronal glutamate can interfere with neuronal migration patterns, differentiation and synaptic development, resulting in varying degrees of abnormal brain architecture and hence differing severities of autistic features.

Glutamate exerts its effect through metabotropic (mGlu) and ionotropic (iGlu) glutamate receptors localized in the cellular membranes of neurons and glia as neuron-supporting cells. According to their differential affinity for different agonists, ionotropic receptors include N-methyl-D-aspartate (NMDA), kainate (KA), and amino3-hydroxy-5-methyl-4-isoxazole propionic acid (AMPA) [3]. The metabotropic receptors belong to the G-proteincoupled receptor, and can be divided into group I (mGluR1 and mGluR5), group II (mGluR2 and mGluR3) and group III (mGluR4 and mGluR6-8) according to their primary sequence and pharmacological agonists [4]. The increased probability of epilepsy in patients with autism suggests enhanced glutamatergic signaling with positive correlation between plasma levels of glutamate and the severity of autism and increased expression of mRNAs encoding the AMPA 1 receptor in the cerebellum of autistic patients $[5,6]$.

While in the adult brain gamma aminobutyric acid (GABA) acts as an inhibitory neurotransmitter, during the perinatal period it depolarizes targeted cells and triggers calcium influx. GABA-mediated calcium signaling regulates a number of important developmental processes which include, cell proliferation, differentiation, synapse maturation, and cell death [7]. A dysfunction of the GABAergic signaling early in development leads to a severe excitatory/inhibitory (E/I) imbalance in neuronal circuits, a condition that may account for some of the behavioral deficits observed in patients with autism [8]. The GABA level, glutamate/GABA and glutamine/glutamate ratios are significantly lower in patients with autism compared to normal controls, thus suggesting a possible abnormality in the regulation between GABA and glutamate that might lead to excitotoxicity $[9,10]$.

The overall aim of this study is to confirm that GABA and glutamate synapses are abnormal in autistic patients and to determine how these abnormalities may be associated with one another and with neuroinflammatory responses as a pathway involved in the etiology of autism.

\section{Material and methods}

\section{Participants and methods}

The study protocol followed the ethical guidelines of the most recent Declaration of Helsinki (Edinburgh, 2000). All subjects enrolled in the study (20 autistic male patients and 19 age- and gender-matched controls) had written informed consent provided by their parents and assented to participate if developmentally able. They were enrolled through the ART Center (Autism Research \& Treatment Center) clinic (Riyadh, Saudi Arabia). The ART Center clinic sample population consisted of children diagnosed on the ASD. The diagnosis of ASD was confirmed in all subjects using the Autism Diagnostic Interview-Revised (ADI-R) and the Autism Diagnostic Observation Schedule (ADOS) and 3DI (Developmental, Dimensional Diagnostic Interview). The ages of all autistic children who participated were between 4 and 12 years old. All were simplex cases. All were negative for fragile X gene study. The control group recruited from Well-baby Clinic at King Khaled University hospital with mean age of 4 to 11 years. Subjects were excluded from the investigation if they had organic aciduria, dysmorphic features, or diagnosis of fragile $\mathrm{X}$ or other serious neurological (for example, seizures), psychiatric (for example, bipolar disorder) or known medical conditions. All participants were screened via parental interview for current and past physical illness. Children with known endocrine, cardiovascular, pulmonary, liver, kidney or other medical diseases were excluded from the study. None of the recruited autistic patients were on special diets or taking alternative treatments.

\section{Ethics approval and consent}

A written consent was obtained from the parents of each individual case, according to the guidelines of the ethical committee of King Khalid Hospital, King Saud University.

\section{Blood samples}

After an overnight fast, $10 \mathrm{ml}$ blood samples were collected from both groups in test tubes containing sodium heparin as anticoagulant. Tubes were centrifuged at 3,500 rpm at room temperature for 15 minutes; plasma was obtained and deep frozen $\left(\right.$ at $-80^{\circ} \mathrm{C}$ ) until analysis.

\section{Determination of GABA}

The quantitative determination of GABA in human plasma was measured using an ELISA diagnostic kit, a product of Immunodiagnostic AG, Dusseldorf, Germany. This assay was based on the method of competitive ELISAs. The sample preparation included the addition of a derivatization reagent for GABA. Afterwards, the treated samples were incubated in wells of a microtiter plate coated with a polyclonal antibody against the GABA derivative, together with an assay reagent containing a GABA-derivative (tracer). During the incubation period, the target GABA in the sample competed with the tracer for the binding of the polyclonal antibodies on the wall of the microtiter wells. GABA in the sample displaced the tracer from binding to the antibodies. Therefore, the concentration of antibody-bound tracer was inversely proportional to the GABA concentration in the sample. A dose-response curve of absorbance 
unit (optical density at $450 \mathrm{~nm}$ ) versus concentration was generated using the values obtained from the standards. GABA present in the patient samples (EDTA plasma) was determined directly from this curve.

\section{Measurement of glutamate}

Glutamate level was assessed using an HPLC method [11]. Plasma samples $(0.1 \mathrm{ml})$ were mixed with $5 \mu \mathrm{l}$ of mercaptoethanol and allowed to stand for 5 minutes at room temperature, then precipitated with ice-cold methanol while being vortexed. Tubes were allowed to stand for 15 minutes in an ice bucket before samples were separated by centrifugation (5,000 rpm for 15 minutes) and the supernatant was collected. The efficiency of the protein precipitation step was assessed by Bradford's dye-binding method [12]. The protein-free supernatants were processed immediately for HPLC analysis of glutamate.

\section{Assay of TNF-a}

TNF- $\alpha$ was measured using a mouse TNF- $\alpha$ ELISA kit (Hycult Biotech, Uden, Netherlands. The antibody reacts with the natural TNF- $\alpha$ of the rats and identifies membrane- as well as receptor-bound TNF- $\alpha$. The TNF$\alpha$ trimer interacts with either of the two types of TNF-R, leading to receptor cross-linking. One unit of Hycult Biotech Mouse TNF- $\alpha$ approximates the bioactivity of 16 units of human TNF- $\alpha$ according to the standard L929 cytotoxicity assays for TNF- $\alpha$ prepared by the World Health Organization (WHO).

\section{Assay of IL-6}

IL-6 was assayed using a Quantikine ELISA kit (R\&D Systems, Minneapolis, MN, USA). A microplate was precoated with a monoclonal antibody specific for rat IL-6. Fifty microliters of each standard, control, or sample were placed in separate wells. The reagent was mixed by gently tapping the plate frame for 1 minute after being covered with the adhesive strip provided. The plate was incubated for 2 hours at room temperature and any rat IL-6 present was bound by the immobilized antibody. After washing away unbound substances, an enzymelinked polyclonal antibody specific for rat IL-6 was added to the wells. Following a subsequent wash step to remove unbound antibody-enzyme reagents, $100 \mu \mathrm{l}$ of substrate solution was added to each well and the plate was incubated for 30 minutes at room temperature. The enzyme reaction yielded a blue product that turned yellow when the stop solution was added. The intensity measured for the color was in proportion to the amount of rat IL-6 bound in the initial step.

\section{Assay of IFN- $\gamma$}

IFN- $\gamma$ was measured using an ELISA kit, a product of Thermo Scientific (Rockford, IL, USA) [13] according to the manufacturer's instructions. This assay employs a quantitative sandwich enzyme immunoassay technique that measures IFN- $\gamma$ in less than 5 hours. The minimum level of rat IFN- $\gamma$ detected by this product was less than $2 \mathrm{pg} / \mathrm{ml}$ read off the standard curve.

\section{Determination of interferon- $\gamma$-inducible protein 16 (IFI16)}

The human IFI16 ELISA kit was provided by BioSource2 Kallang Avenue, 06-32, Singapore 339407. This immunoassay kit allows for the in vitro quantitative determination of human IFI16 concentrations in plasma. The IFI16 ELISA kit applied the quantitative sandwich enzyme immunoassay technique. The microtiter plate had been pre-coated with a monoclonal antibody specific for IFI16. Standards or samples were then added to the microtiter plate wells and IFI16, if present, bound to the antibody precoated wells. In order to quantitatively determine the amount of IFI16 present in the sample, a standardized preparation of horseradish peroxidase (HRP)-conjugated polyclonal antibody, specific for IFI16, was added to each well to 'sandwich' the IFI16 immobilized on the plate. The microtiter plate then underwent incubation, and the wells were subsequently thoroughly washed to remove all unbound components. Next, substrate solutions were added to each well. The enzyme HRP and substrate were allowed to react over a short incubation period. Only those wells that contained IFI16 and HRP-conjugated antibody exhibited a change in color. The enzyme-substrate reaction was terminated by the addition of a sulfuric acid solution and the color change was measured spectrophotometrically at a wavelength of $450 \mathrm{~nm}$. A standard curve was plotted relating the intensity of the color (optical density) to the concentration of standards. The IFI16 concentration in each sample was interpolated from this standard curve.

\section{Results}

Levels of glutamate, GABA, glutamate/GABA, TNF- $\alpha$, IL6 , IFN- $\gamma$ and IFI16 were compared between patients with autism and age-matched control subjects. Data are presented as a mean \pm SD of a number of 20 patients with ASD compared to 19 controls, and the significant difference between both groups was presented in Table 1. It was noticed that the six measured parameters differed significantly between patients and controls. Figures 1, 2 and 3 demonstrate individual data distribution around the mean value represented as a straight line for the studied parameters. Table 1 also represents the percentage increase or decrease of the measured parameters of autistic patients relative to control subjects. It can be easily observed that GABA and glutamate recorded 57 and $36 \%$ increase respectively in autistic compared to control subjects and about 13\% decrease in glutamate/ GABA ratio. Table 1 also shows about 25\% decrease in 
Table 1 Levels of the measured parameters in plasma of autistic patients compared to control

\begin{tabular}{|c|c|c|c|c|c|}
\hline Parameter & Group & $\mathrm{N}$ & Mean \pm SD & Percent change & $P$-value \\
\hline \multirow[t]{2}{*}{ GABA $(\mu \mathrm{mol} / \mathrm{l})$} & Control & 19 & $0.53 \pm 0.05$ & 100.00 & 0.001 \\
\hline & Autistic & 20 & $0.83 \pm 0.12$ & 157.71 & \\
\hline \multirow[t]{2}{*}{ Glutamate $(\mu \mathrm{mol} / \mathrm{l})$} & Control & 19 & $111.91 \pm 4.63$ & 100.00 & 0.001 \\
\hline & Autistic & 20 & $152.80 \pm 6.47$ & 136.54 & \\
\hline \multirow[t]{2}{*}{ Glutamate/GABA ratio } & Control & 19 & $214.72 \pm 22.26$ & 100.00 & 0.003 \\
\hline & Autistic & 20 & $188.12 \pm 30.11$ & 87.61 & \\
\hline \multirow[t]{2}{*}{ IL-6 } & Control & 19 & $363.49 \pm 22.88$ & 100.00 & 0.001 \\
\hline & Autistic & 20 & $273.87 \pm 32.49$ & 75.34 & \\
\hline \multirow[t]{2}{*}{ TNF-a } & Control & 19 & $346.23 \pm 24.95$ & 100.00 & 0.001 \\
\hline & Autistic & 20 & $252.35 \pm 63.60$ & 72.89 & \\
\hline \multirow[t]{2}{*}{ INF-Y (ng/ml) } & Control & 19 & $50.85 \pm 5.71$ & 100.00 & 0.001 \\
\hline & Autistic & 20 & $85.33 \pm 9.06$ & 167.80 & \\
\hline \multirow[t]{2}{*}{ IFl16 (ng/ml) } & Control & 19 & $1.91 \pm 0.60$ & 100.00 & 0.001 \\
\hline & Autistic & 20 & $3.11 \pm 1.01$ & 162.49 & \\
\hline
\end{tabular}

Table 1 describes the independent samples $t$-test between the control and autistic groups for all parameters.

TNF- $\alpha$, IL- 6 and around 65 and $62 \%$ increase of IFN- $\gamma$ and IFI16 respectively.

Table 2 and Figure 4 (a-d) demonstrate the receiver operating characteristics (ROC) analysis data as area under the curve (AUC), cutoff values, specificity, and sensitivity of the measured parameters. All parameters exhibited AUC values close to 1 and satisfactory values of accuracy presented as high specificity and sensitivity.

Tables 3, 4 and 5 demonstrate the multiple regression analysis between the measured parameters using GABA, glutamate and glutamate/GABA as dependent variables respectively.

\section{Discussion}

GABA and glutamate are the main inhibitory and excitatory neurotransmitters in the human brain. Both have critical roles during early development of the nervous system, a stage when clinical presentation indicates that autism begins. Therefore, it is important to understand the functional status of GABAergic and glutamatergic neurotransmission in the plasma as the body fluid reflects brain physiology and pathology. Clarification of the relationship between abnormality in the absolute and relative GABAergic and glutamatergic synaptic activities and neuroinflammatory biomarkers represented by TNF- $\alpha$, IL-6, IFN- $\gamma$, and IFI16 could help to find a target for pharmacological intervention.

Brain GABA and glutamate metabolism include a series of integrated and interconverted pathways. Glutamate, in addition to its importance in the clearance of brain ammonia through glutamine synthesis, serves as an important energy source through the tricarboxylic acid cycle

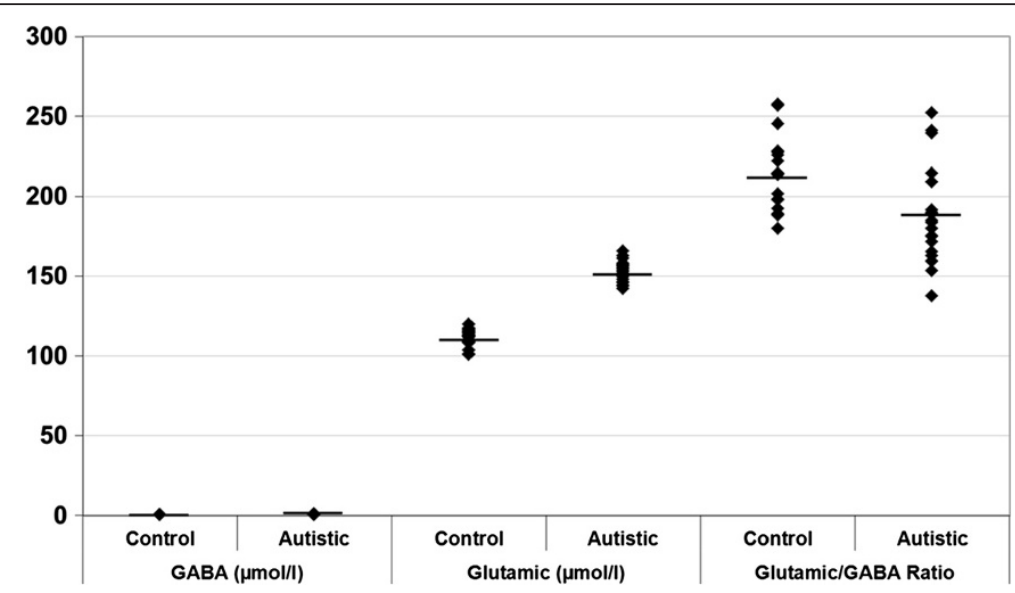

Figure $1 \mathrm{Gamma}$ aminobutyric acid (GABA) ( $\mu \mathrm{mol} / \mathrm{l})$, glutamate $(\mu \mathrm{mol} / \mathrm{l})$ and glutamate/GABA ratio in control and autistic patients. The mean value for each group is designated by a line. 


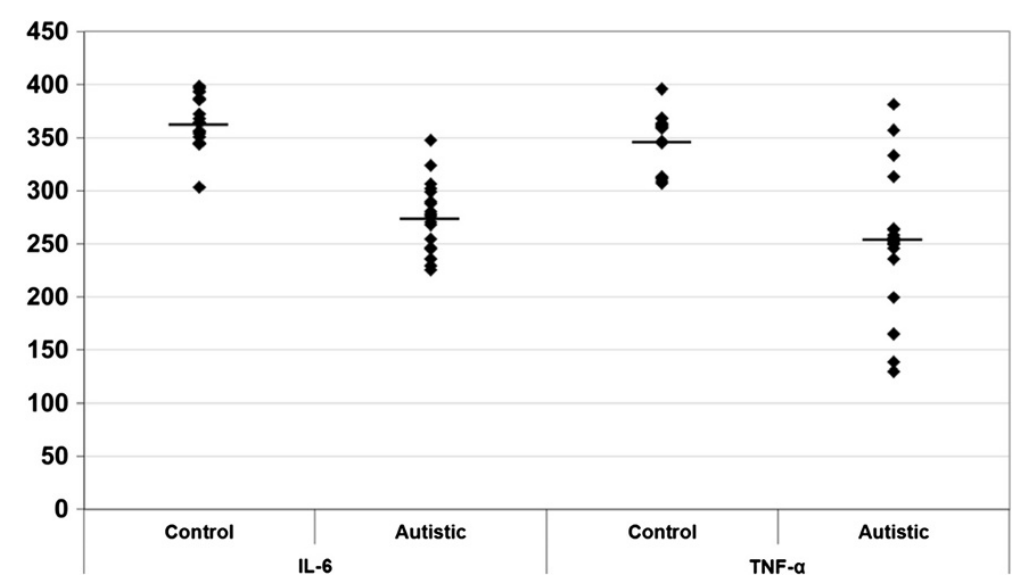

Figure 2 IL- 6 and TNF- $\boldsymbol{a}$ in control and autistic patients. The mean value for each group is designated by a line.

(TCA) cycle after its deamination by glutamate dehydrogenase and oxidative decarboxylation by $\alpha$-ketoglutarate dehydrogenase. Glutamate is converted to GABA by glutamic acid decarboxylase. Finally, GABA is metabolized to succinate by the combined reactions of GABA transaminase and succinic semialdehyde dehydrogenase. The significant increase of the absolute concentration of both neurotransmitters reported in the present study, together with the remarkable decrease in the glutamate/GABA ratio in autistic patients compared to healthy controls (Table 1), can be easily related to autistic characteristics. Since GABA derives from glutamate and glutamate derives from GABA, alterations in both neurotransmitters can affect each other. The unexpected elevation of GABA as an inhibitory neurotransmitter in autistic patients with a high rate of onset of epilepsy could be explained on the basis that high plasma GABA could be concomitant with lower brain GABA due to a smaller number or dysfunctional neuronal GABA receptors. GABA exerts its functions by binding to chloride-permeable ionotropic $\mathrm{GABA}_{\mathrm{A}}$ receptors and metabotropic $\mathrm{GABA}_{\mathrm{B}}$ receptors. This explanation can be acceptable because GABAergic transmission through receptors is achieved by different mechanisms such as modulation of $\mathrm{GABA}_{\mathrm{A}}$ receptors and variation of intracellular chloride concentration together with alteration in GABA concentration [14]. Elevation of GABA level, which was recorded in the present study, can be easily related to the significant elevation of glutamate as substrate of glutamate decarboxylase. The suggested role of GABA receptors in the excitotoxicity or inhibitory/ excitatory imbalance in autistic patient could be supported through the recent work of Han et al. [15] in which low doses of benzodiazepines increase inhibitory neurotransmission through positive allosteric modulation of post-synaptic $\mathrm{GABA}_{\mathrm{A}}$ receptors, improved impaired social interaction, repetitive behavior, and cognitive ability in an animal model of autism. In contrast, negative allosteric modulation of $\mathrm{GABA}_{\mathrm{A}}$ receptors impaired social behavior in wild-type mice, supporting the notion that

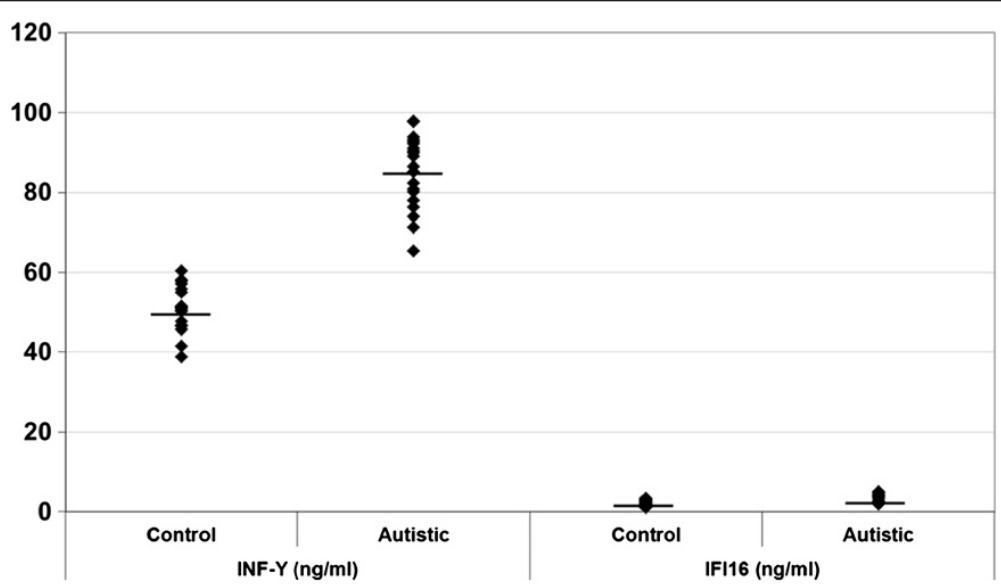

Figure 3 INF- $\gamma(\mathbf{n g} / \mathrm{ml})$ and IFI16 $(\mathbf{n g} / \mathrm{ml})$ in control and autistic patients. The mean value for each group is designated by a line. 
Table 2 Receiver operating characteristics (ROC) curve of all parameters in autistic groups

\begin{tabular}{|c|c|c|c|c|}
\hline & Area under the curve & Best cutoff value & Sensitivity \% & Specificity $\%$ \\
\hline GABA $(\mu \mathrm{mol} / \mathrm{l})$ & 1.000 & 0.617 & $100.0 \%$ & $100.0 \%$ \\
\hline Glutamate $(\mu \mathrm{mol} / \mathrm{l})$ & 1.000 & 131.110 & $100.0 \%$ & $100.0 \%$ \\
\hline Glutamate/GABA ratio & 0.787 & 191.792 & $75.0 \%$ & $84.2 \%$ \\
\hline IL-6 & 0.984 & 333.840 & $95.0 \%$ & $94.7 \%$ \\
\hline TNF-a & 0.903 & 285.530 & $80.0 \%$ & $100.0 \%$ \\
\hline INF-y (ng/ml) & 1.000 & 62.780 & $100.0 \%$ & $100.0 \%$ \\
\hline $\mathrm{IFl16}(\mathrm{ng} / \mathrm{ml})$ & 0.864 & 1.860 & $100.0 \%$ & $63.2 \%$ \\
\hline
\end{tabular}

reduced inhibitory neurotransmission may contribute to social and cognitive deficits as autistic characteristics.

The recorded decrease of IL- 6 and TNF- $\alpha$ in plasma of autistic patients compared to control healthy participants (Table 1) could be a consequence of an early elevation of these cytokines in plasma followed by influx of both to the brain across the blood-brain barrier (BBB). This explanation can be supported by many studies that proved the elevation of IL-6 in autistic brains [16]. Although elevation of IL- 6 is a repeated finding in autism, the exact mechanism by which an IL- 6 increase may contribute to the pathogenesis of this disorder remains undefined. The association between IL- 6 and low glutamate/ GABA ratio (Table 5) observed in the present study, could help in clarifying this mechanism. Firstly, a key role for inhibitory/excitatory imbalance in autism is supported by the fact that 10 to $30 \%$ of autistic patients suffer from epilepsy [17]. This synaptic abnormality hypothesis was

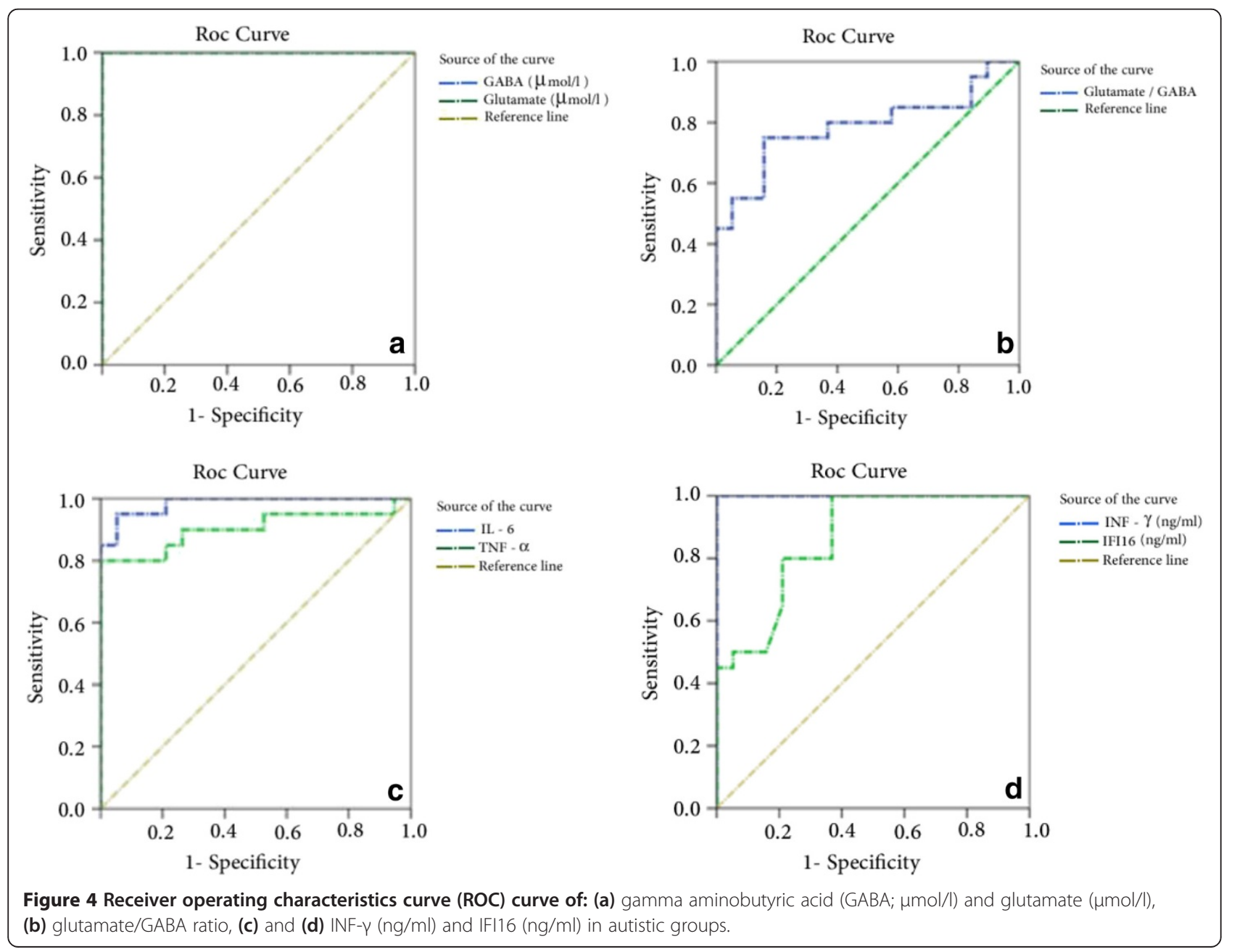


Table 3 Multiple regression using stepwise method for gamma aminobutyric acid (GABA; $\mu \mathrm{mol} / \mathrm{l})$ as a dependent variable

\begin{tabular}{|c|c|c|c|c|c|}
\hline \multirow{2}{*}{$\begin{array}{l}\text { Predictor } \\
\text { variable }\end{array}$} & \multirow[t]{2}{*}{ Beta } & \multirow[t]{2}{*}{$P$-value } & \multirow[t]{2}{*}{ Adjusted ${ }^{2} \mathrm{R}$} & \multicolumn{2}{|l|}{ Model } \\
\hline & & & & F-value & $P$-value \\
\hline Glutamate $(\mu \mathrm{mol} / \mathrm{l})$ & 0.617 & 0.001 & 0.973 & 687.641 & 0.001 \\
\hline $\begin{array}{l}\text { Glutamate/ } \\
\text { GABA ratio }\end{array}$ & -0.589 & 0.001 & & & \\
\hline
\end{tabular}

further supported by the identification of mutations affecting synaptic cell adhesion molecules, as well as synaptic proteins in autistic subjects [18-20]. Secondly, IL-6 elevation was found to stimulate excitatory synapse formation and impair the development of inhibitory synapses. This role of IL-6 was supported by the detection of a reduced post-excitatory inhibition in IL-6 overexpressed mice. Post-excitatory inhibition, which is usually measured by paired-pulse inhibition (PPI) has been suggested as being caused by a reduction in the release of glutamate from terminals of afferent axons [21,22]. This effect seems to be the result of an inhibition of calcium influx through presynaptic receptors, which play a critical role in the release of glutamate from synaptic vesicles on afferent stimulation [23,24]. Thirdly, mice with elevated IL-6 in the brain display many autistic features, including impaired cognitive abilities, deficits in learning, abnormal anxiety traits and habituations, as well as decreased social interactions [13].

The suggested increase of brain TNF- $\alpha$ and the association between this cytokine and the impaired glutamate/ GABA ratio reported in the present study (Table 5) could be explained on the basis of the interesting relationship between neurons, glial cells and TNF- $\alpha$ leading to glutamate excitotoxicity [25]. In general, excitotoxicity is related to the activation of NMDA receptors by excessive glutamate. Brain cell death usually occurs after over stimulation of glutamate receptors due to impaired reuptake of glutamate by the EAAT2/GLT-1 transporters on glial cells [26]. The expression of this transporter has been shown to be regulated by NF- $\kappa \mathrm{B}$ [27]. Pickering et al. [28] showed that increased levels of TNF- $\alpha$ might be easily related to glutamate excitotoxicity through the decrease of EAAT2/GLT-1 expression. TNF- $\alpha$ induces the classical I kappa B ( $\mathrm{I} \kappa \mathrm{B})$ degradation pathway to

Table 4 Multiple regression using stepwise method for glutamate $(\mu \mathrm{mol} / \mathrm{l})$ as a dependent variable

\begin{tabular}{llllll}
\hline $\begin{array}{l}\text { Predictor } \\
\text { variable }\end{array}$ & Beta & $\boldsymbol{P}$-value & Adjusted $^{2} \mathbf{R}$ & Model & \\
\cline { 5 - 6 } & & & & F-value & $\boldsymbol{P}$-value \\
\hline INF- $(\mathrm{ng} / \mathrm{ml})$ & 0.594 & 0.001 & 0.869 & 85.107 & 0.001 \\
TNF-a & -0.238 & 0.003 & & & \\
IL-6 & -0.221 & 0.026 & & & \\
\hline
\end{tabular}

Table 5 Multiple regression using stepwise method for glutamate/gamma aminobutyric acid (GABA) ratio as a dependent variable

\begin{tabular}{|c|c|c|c|c|c|}
\hline \multirow{2}{*}{$\begin{array}{l}\text { Predictor } \\
\text { variable }\end{array}$} & \multirow[t]{2}{*}{ Beta } & \multirow[t]{2}{*}{$P$-value } & \multirow[t]{2}{*}{ Adjusted ${ }^{2} \mathrm{R}$} & \multicolumn{2}{|l|}{ Model } \\
\hline & & & & F-value & $P$-value \\
\hline GABA $(\mu \mathrm{mol} / \mathrm{l})$ & -1.545 & 0.001 & 0.935 & 183.521 & 0.001 \\
\hline Glutamate $(\mu \mathrm{mol} / \mathrm{l})$ & 1.049 & 0.001 & & & \\
\hline IL-6 & 0.157 & 0.036 & & & \\
\hline
\end{tabular}

trigger NF- $\kappa \mathrm{B}$ nuclear translocation and DNA binding to repress EAAT2 expression. In this situation, the presence of elevated TNF- $\alpha$ concentrations leads to elevated extracellular glutamate concentration, thereby increasing the risk of glutamate excitotoxicity. Elevated TNF- $\alpha$ concentrations could be also contributed to the decrease of the inhibitory transmission. Recently, an in vitro culture study in mature rat and mouse hippocampal neurons demonstrated that acute (45 minute) application of TNF- $\alpha$ induced a rapid and persistent decrease of inhibitory synaptic strength as well as a downregulation of cell-surface levels of $\mathrm{GABA}_{\mathrm{A}}$ receptors [29].

Table 1 demonstrates the large significant increase of IFN- $\gamma$ in plasma of autistic patients compared to healthy control participants. This increase was associated with the low glutamate/GABA ratio representing inhibitory/ excitatory synaptic transmission (Table 5). This association could be reasonably accepted and explained on the basis of the key role of IFN- $\gamma$ in the induction of neurotoxicity. Recently, it has been proposed that IFN- $\gamma$ directly induces neuronal dysfunction through the formation of dendritic beads in mouse cortical neurons and the enhancement of glutamate neurotoxicity via AMPA but not NMDA receptors. IFN- $\gamma$ forms a unique, neuronspecific, calcium-permeable receptor complex with AMPA receptor subunit GluR1. Through this receptor complex, IFN- $\gamma$ phosphorylates GluR1 at serine 845 position by the JAK1-2/STAT1 pathway, increases $\mathrm{Ca}^{+2}$ influx and nitric oxide production, and subsequently decreases ATP production, leading to the dendritic bead formation. This explanation could provide a mechanisms through which inflammation could be related to glutamate excitotoxicity as an etiological signaling involved in autism pathology [30].

ROC analyses of glutamate, GABA, glutamate/GABA, TNF- $\alpha$, IL-6, IFN- $\gamma$ and IFI1 6 are presented in Table 2 and Figures 4 (a-d). All measured parameters demonstrated satisfactory sensitivity and very high specificity, which confirmed the hypothesis that autistic patients are characterized by excitotoxicity and suffer from neuroinflammation.

Multiple regression analysis, as one of the most powerful methods of data analysis, was used between the measured parameters to determine the relative contribution of impaired GABAergic and glutamatergic 
neurotransmission in the recorded neuroinflammation and to predict the role of the measured cytokines in the glutamatergic/GABAergic imbalance in autistic patients compared to healthy control subjects (Tables 3, 4 and 5).

The finding that the high plasma GABA levels are positively correlated to glutamate and glutamate/GABA levels (Table 3) led us to propose that the unexpected increase in GABA concentration in autistic patients is induced partly by glutamate bioavailability as substrate to glutamate decarboxylase (GAD) enzyme. This can be supported by the value of $\mathrm{R}^{2}$, which shows that 0.973 or $97 \%$ of the variance in GABA was related to the elevation of glutamate. Despite the elevated GABA in plasma of autistic patients, a dysfunction in inhibitory GABAergic transmission is suggested due to a reduced density of $\mathrm{GABA}_{\mathrm{A}}$ receptors in the hippocampus [31,32], reduced $\mathrm{GABA}_{\mathrm{A}}$ and $G_{A B A}$ receptor protein subunits in the cerebellum, prefrontal Brodmann area 9 and parietal Brodmann area $40[33,34]$, and a reduced expression of the GABAsynthesizing iso-enzymes GAD65 and GAD67 in the parietal and cerebellar cortices in autistic brains [35].

Table 4 demonstrates the stepwise multiple regression analysis using glutamate as dependent variable and TNF- $\alpha$, IL-6, IFN- $\gamma$ and IFI16 as independent variables. The value of $\mathrm{R}^{2}$ shows that 0.869 or almost $87 \%$ of the variance in glutamate was explained by, or related to, neuroinflammation as discussed above. While, IFN- $\gamma$ cytokine was the most significantly related to glutamate excitotoxicity, IFI16 did not contribute.

\section{Conclusion}

Based on the present study, it could be concluded that glutamate/GABA balance or excitatory/inhibitory balance is crucial for the functioning of the synapse. Multiple mechanisms may compromise this balance; neuroinflammation highly contributes to the imbalance and consequently to the etiology of autism.

\footnotetext{
Abbreviations

GABA: gamma aminobutyric acid; TNF-a: tumor necrosis factor alpha; IL-6: interlukin-6; IFN- $\gamma$ : interferon gamma; IFI16: interferon -induced protein 16; (mGlu R): metabotropic glutamate receptors; (iGlu R): ionotropic glutamate receptors; EDTA: ethylene-diamine-tetra-acetic acid.
}

\section{Competing interests}

The authors declare that they have no competing interests.

\section{Authors' contributions}

AE: designed the study, performed the work and data analysis and drafted the manuscript. The author has read the final manuscript. Both authors read and approved the final manuscript.

\section{Acknowledgments}

This research project was supported by a grant from the Research Center of the Center for Female Scientific and Medical Colleges in King Saud University.

\section{Author details}

${ }^{1}$ Biochemistry Department, Science College, King Saud University, PO box 22452, 11495 Riyadh, Saudi Arabia. ${ }^{2}$ Autism Research and Treatment Center, Riyadh, Saudi Arabia. ${ }^{3}$ Shaik Al-Amodi Autism Research Chair, King Saud University, Riyadh, Saudi Arabia. ${ }^{4}$ Department of Physiology, Faculty of Medicine, King Saud University, Riyadh, Saudi Arabia. ${ }^{5}$ Medicinal Chemistry Department, National Research Center, Dokki, Cairo, Egypt.

Received: 19 September 2014 Accepted: 27 October 2014

Published online: 19 November 2014

\section{References}

1. Blaylock RL: Chronic microglial activation and excitotoxicity secondary to excessive immune stimulation: possible factors in Gulf War syndrome and autism. J Am Physicians Surg 2004, 9(2):46-51.

2. McGeer PL, McGeer EG: Local neuroinflammation and the progression of Alzheimer's disease. J Neurovirol 2002, 8:529-538.

3. Dingledine R, Borges K, Bowie D, Traynelis SF: 'The glutamate receptor ion channels'. Pharmacol 1999, 51(1):7-61.

4. Fagni L, Ango F, Perroy J, Bockaert J: 'Identification and functional roles of metabotropic glutamate receptor-interacting proteins'. Semin Cell Dev Biol 2004, 15(3):289-298.

5. Tuchman R, Rapin I: 'Epilepsy in autism'. Lancet Neurol 2002, 6(1):352-358.

6. Shinohe A, Hashimoto K, Nakamura K, Tsujii M, Iwata Y, Tsuchiya KJ, Sekine Y, Suda S, Suzuki K, Sugihara G, Matsuzaki H, Minabe Y, Sugiyama T, Kawai M, lyo M, Takei N, Mori N: 'Increased serum levels of glutamate in adult patients with autism'. Prog Neuropsychopharmacol Biol Psychiatry 2006, 30(8):1472-1477.

7. Owens DF, Kriegstein AR: Is there more to GABA than synaptic inhibition? Nat Rev Neurosci 2002, 9:715-727.

8. Pizzarelli R, Cherubini E: Alterations of GABAergic signaling in autism spectrum disorders. Hindawi Publishing Corporation. Neural Plast, 2011:297153. 12 pages doi:10.1155/2011/297153.

9. Abu Shmais GA, Al-Ayadhi LY, Al-Dbass AM, El-Ansary AK: Mechanism of nitrogen metabolism-related parameters and enzyme activities in the pathophysiology of autism. J Neurodev Disord 2012, 4(1):4.

10. Harada M, Taki MM, Nose A, Kubo H, Mori K, Nishitani H, Matsuda T: Non-invasive evaluation of the GABAergic/glutamatergic system in autistic patients observed by MEGA-editing proton MR spectroscopy using a clinical 3 tesla instrument. J Autism Dev Disord 2011, 41(4):447-454.

11. Suresh Babu VS, Shareef MM, Pavan Kumar Shetty A, Taranath Shetty K: HPLC method for amino acids profile in biological fluids and inborn metabolic disorders of aminoacidopathies. Indian J Clin Biochem 2002, 17(2):7-26.

12. Bradford M: A rapid and sensitive method for the quantification of micrograms quantities of protein utilizing the principle of protein dyebinding. Anal Biochem 1976, 76:248-254.

13. Wei H, Zou H, Sheikh A, Malik M, Dobkin C, Brown T, Li X: IL-6 is increased in the cerebellum of the autistic brain and alters neural cell adhesion, migration and synapse formation. J Neuroinflammation 2011, 8:52.

14. Deidda G, Bozarth IF, Cancedda L: Modulation of GABAergic transmission in development and neurodevelopmental disorders: investigating physiology and pathology to gain therapeutic perspectives. Front Cell Neurosci 2014, 8:119.

15. Han S, Tai C, Jones CJ, Scheuer T, Catterall WA: Enhancement of inhibitory neurotransmission by GABAA receptors having a2,3-subunits ameliorates behavioral deficits in a mouse model of autism. Neuron 2014 81(6):1282-1289.

16. Vargas DL, Nascimbene C, Krishnan C, Zimmerman AW, Pardo CA: Neuroglial activation and neuroinflammation in the brain of patients with autism. Ann Neurol 2005, 57:67-81.

17. Li X, Chauhan A, Sheikh AM, Patil S, Chauhan V, Li XM, Ji L, Brown T, Malik M: Elevated immune response in the brain of autistic patients. J Neuroimmunol 2009, 207:111-116.

18. Canitano R: Epilepsy in autism spectrum disorders. Eur Child Adolesc Psychiatry 2007, 16:61-66.

19. Durand CM, Betancur C, Boeckers TM, Bockmann J, Chaste P, Fauchereau F, Nygren G, Rastam M, Gillberg IC, Anckarsater H, Sponheim E, GoubranBotros H, Delorme R, Chabane N, Mouren-Simeoni MC, de Mas P, Bieth E, Roge B, Heron D, Burglen L, Gillberg C, Leboyer M, Bourgeron T: Mutations 
in the gene encoding the synaptic scaffolding protein SHANK3 are associated with autism spectrum disorders. Nat Genet 2007, 39:25-27.

20. Abrahams BS, Geschwind DH: Advances in autism genetics: on the threshold of a new neurobiology. Nat Rev Genet 2008, 9:341-355.

21. Morrow EM, Yoo SY, Flavell SW, Kim TK, Lin Y, Hill RS, Mukaddes NM, Balkhy S, Gascon G, Hashmi A, Al-Saad S, Ware J, Joseph RM, Greenblatt R, Gleason D, Ertelt JA, Apse KA, Bodell A, Partlow JN, Barry B, Yao H, Markianos K, Ferland RJ, Greenberg ME, Walsh CA: Identifying autism loci and genes by tracing recent shared ancestry. Science 2008, 321:218-223.

22. Levenes C, Daniel H, Soubrie P, Crepel F: Cannabinoids decrease excitatory synaptic transmission and impair long-term depression in rat cerebellar Purkinje cells. J Physiol 1998, 510(3):867-879.

23. Szabo B, Wallmichrath I, Mathonia P, Pfreundtner C: Cannabinoids inhibit excitatory neurotransmission in the substantia nigra pars reticulata. Neuroscience 2000, 97:89-97.

24. Neher E: Vesicle pools and Ca2+ microdomains: new tools for understanding their roles in neurotransmitter release. Neuron 1998, 20:389-399

25. Olmos G, Lladó J: Tumor necrosis factor alpha: a link between neuroinflammation and excitotoxicity. Mediat Inflamm 2014, Article ID 861231,12 pages.

26. Rothstein JD, Martin LJ, Kuncl RW: Decreased glutamate transport by the brain and spinal cord in amyotrophic lateral sclerosis. N Engl J Med 1992, 326:1464-1468.

27. Ghosh M, Yang Y, Rothstein JD, Robinson MB: Nuclear factor-B contributes to neuron-dependent induction of glutamate transporter-1 expression in astrocytes. J Neurosci 2011, 31(25):9159-9169.

28. Pickering M, Cumiskey D, O'Connor JJ: Actions of TNF-alpha on glutamatergic synaptic transmission in the central nervous system. Exp Physiol 2005, 90(5):663-670

29. Pribiag H, Stellwagen D: TNF-alpha downregulates inhibitory neurotransmission through protein phosphatase 1-dependent trafficking of $\mathrm{GABA}_{\mathrm{A}}$ receptors. J Neurosci 2013, 33(40):15879-15893.

30. Mizuno T, Zhang G, Takeuchi H, Kawanokuchi J, Wang J, Sonobe Y, Jin S, Takada N, Komatsu Y, Suzumura A: Interferon-gamma directly induces neurotoxicity through a neuron specific, calcium-permeable complex of IFN-gamma receptor and AMPA GluR1 receptor. FASEB J 2008, 22(6):1797-1806

31. Blatt GJ, Yip J, Soghomonian J-J, Whitney E, Thevarkunnel S, Bauman ML, Kemper TL: An emerging GABA/glutamate hypothesis of cerebellar dysfunction in autism. Int Meet Autism Res 2007, 6:144

32. Guptill JT, Booker AB, Gibbs TT, Kemper TL, Bauman ML, Blatt GJ: $[3 \mathrm{H}]$-flunitrazepam labeled benzodiazepine binding sites in the hippocampal formation in autism: a multiple concentration autoradiographic study. J Autism Dev Disord 2007, 37:911-920.

33. Fatemi SH, Folsom TD, Reutiman TJ, Thuras PD: GABA(A) receptor down regulation in brains of subjects with autism. Cerebellum 2009, 8:64-69.

34. Fatemi SH, Halt AR, Stary JM, Kanodia R, Schulz SC, Realmuto GR: Glutamic acid carboxylase 65 and $67 \mathrm{kDa}$ proteins are reduced in autistic parietal and cerebellar cortices. Biol Psych 2002, 52:805-810.

35. Fatemi SH, Reutiman TJ, Folsom TD, Thuras PD: GABA(A) receptor down regulation in brains of subjects with autism. J Autism Dev Disord 2009, 39:223-230.

doi:10.1186/s12974-014-0189-0

Cite this article as: El-Ansary and Al-Ayadhi: GABAergic/glutamatergic imbalance relative to excessive neuroinflammation in autism spectrum disorders. Journal of Neuroinflammation 2014 11:189.

\section{Submit your next manuscript to BioMed Central and take full advantage of:}

- Convenient online submission

- Thorough peer review

- No space constraints or color figure charges

- Immediate publication on acceptance

- Inclusion in PubMed, CAS, Scopus and Google Scholar

- Research which is freely available for redistribution

Submit your manuscript at www.biomedcentral.com/submit
Ciomed Central 